\title{
Awe in Childhood: Conjectures About a Still Unexplored Research Area
}

\author{
Claire Prade* \\ Department of Developmental and Differential Psychology, Research Center for the Psychology of Knowledge, Language, \\ and Emotion, Aix-Marseille University, Aix-en-Provence, France
}

Keywords: self-development, emotions in children, awe experiences, cognitive accommodation, self-awareness, self-transcendent emotions

Throughout his life, Albert Einstein would retain the intuition and the awe of a child. He never lost his sense of wonder at the magic of nature's phenomena-magnetic fields, gravity, inertia, acceleration, light beams-which grown-ups find so commonplace. He retained the ability to hold two thoughts in his mind simultaneously, to be puzzled when they conflicted, and to marvel when he could smell an underlying unity. "People like you and me never grow old," he wrote a friend later in life. "We never cease to stand like curious children before the great mystery into which we were born."

—Walter Isacsoon, Einstein: His Life and Universe

\section{OPEN ACCESS}

Edited by:

Alice Chirico,

Catholic University of the Sacred

Heart, Italy

Reviewed by:

Lisbeth Carolina Bethelmy Rincón, Simón Bolivar University, Venezuela

*Correspondence:

Claire Prade

claire.prade@gmail.com

Specialty section:

This article was submitted to

Positive Psychology,

a section of the journal

Frontiers in Psychology

Received: 08 October 2021

Accepted: 06 January 2022

Published: 28 January 2022

Citation:

Prade C (2022) Awe in Childhood: Conjectures About a Still Unexplored

Research Area.

Front. Psychol. 13:791534 doi: 10.3389/fpsyg.2022.791534
In his famous biography of Albert Einstein, Walter Isaacson shared the idea that awe might be a particularly important emotion during childhood, notably in the process of knowledge acquisition and learning. In the conclusion of a recent scientific publication, Valdesolo et al. (2017) made similar assumptions. Indeed, given that awe is triggered by a need for cognitive accommodation (Keltner and Haidt, 2003; Campos et al., 2013) and that cognitive accommodation underlies learning from an early age Piaget and Inhelder (1969/1969), Valdesolo et al. (2017) claimed that awe may be deeply involved in the process of early learning. The present article aims to specify this assumption. In a first part, features of awe and its differences with other epistemic emotions will be examined. Afterwards, conjectures about the emergence and development of awe in childhood will be made in order to understand the involvement of awe in early learning.

\section{FEATURES OF AWE}

Awe has been theorized as the emotional response to strikingly vast or powerful stimuli that challenge the individuals' current frames of reference (Keltner and Haidt, 2003) and therefore cause them to rethink their understanding of the world (e.g., Saroglou et al., 2008; Büssing et al., 2021; Stancato and Keltner, 2021). In other words, two appraisals are needed to be met to experience awe: perception of vastness and a need for knowledge restructuring (Keltner and Haidt, 2003; Campos et al., 2013; Shiota et al., 2014).

Knowledge restructuring, also labeled cognitive accommodation, refers to the process of adjusting mental structures that cannot assimilate a new experience into preexisting schemas (Piaget and Inhelder, 1969/1969). Valdesolo et al. (2017, p. 3) claimed that "it is the accommodative component of the awe experience that distinguishes it from other epistemic emotions." However, the process of restructuring cognition when new information contradicts prior knowledge or personal beliefs seems to be a common feature of all epistemic emotions, such as curiosity, interest, confusion, and awe (Campos et al., 2013; Vogl et al., 2019; see also Muis et al., 2018). Indeed, epistemic emotions are defined as emotions resulting from information-oriented appraisals about one's knowledge gap (see Silvia, 2010; Muis et al., 2018). Consequently, what distinguishes the awe experience from other related epistemic emotional experiences may not to be the need for accommodation but the physical or conceptual vastness of its elicitors (Keltner and Haidt, 2003; Campos et al., 2013). Moreover, recent findings demonstrated that awe is elicited by appraisals 
linked to exceeded expectancies rather than those that are only linked to disconfirmed expectancies; that is vastness would be central to awe while inconsistency would be peripheral to it (Gocłowska et al., 2021).

According to Keltner and Haidt (2003, p. 303), "vastness refers to anything that is experienced as being much larger than the self, or the self's ordinary level of experience or frame of reference." Vastness can refer to physical, social, temporal, or any other conceptual dimension of an entity. Grand vista, natural phenomena, self-transcendent music, or monumental architecture are thus common stimuli of awe (Shiota et al., 2007; Ji et al., 2019; Negami and Ellard, 2021). Consequently, awe has been classified amongst self-transcendent emotions (i.e., emotions triggered by what is greater than the self and beyond its perceived boundaries; Shiota et al., 2014).

In order to catch the complexity of an emotion, it is relevant to focus both on its antecedents and consequences. During the last two decades, an increasing number of researchers have devoted their attention to highlight the effects of awe experiences on individuals. For example, awe has been found to diminish the sense of self (Bai et al., 2017; Sturm et al., 2020), and to promote spirituality (Saroglou et al., 2008; Van Cappellen and Saroglou, 2012), prosociality (Piff et al., 2015; Prade and Saroglou, 2016), humility (Stellar et al., 2018), environmentalism (Zhao et al., 2018), and well-being (Rudd et al., 2012; Bai et al., 2021). However, researchers who investigated awe, and how this emotion influence intraindividual and interpersonal changes, have primarily focused on the adult. Theoretical and empirical research on awe experiences during childhood is still dire missing. Yet, investigating awe in children may provide crucial information necessary for a better understanding of this emotion, its appraisals, consequences, and functions. Moreover, exploring how awe emerges and develops throughout childhood may have important implications for education, well-being, or recreational fields.

\section{EMERGENCE AND DEVELOPMENT OF AWE IN CHILDHOOD}

While cognitive accommodation is an innate learning process (Piaget and Inhelder, 1969/1969), the ability to perceive vastness presumably relies on the development of advanced cognitive skills therefore may not be present from birth. Vastness refers to what is perceived as being larger than the self. Thus, to experience vastness, children must presumably have the ability to form stable representations of the self and the world, then must be able to compare the stimulus to those representations. To perceive an entity as being greater than oneself presupposes having a sense of self.

Infants as young as 6 months old are able to detect a difference in the size of two stimuli (e.g., Brannon et al., 2006). However, detecting that one stimulus is bigger than another does not imply than it is perceived as vast. As mentioned, perceiving vastness presupposes a sense of self and self-evaluative processes skills. Based on the mirror self-recognition paradigm, most developmental and comparative psychologists consider that is not prior to $\sim 18-24$ months that children begin to show a sense of self, or self-awareness (for reviews on early self-awareness; see Diehl et al., 2011; Morin, 2021). At this age, however, toddlers only show physical self-awareness which remains relatively inconsistent during months; infants oscillate between self-recognition and the perception of seeing someone else facing them until $\sim 4$ years (see Rochat, 2003). As selfawareness is a prerequisite to the perception of vastness, first awe experiences could not appear before 18-24 months and would more probably emerge after 4 years; they may be slinking and exclusively triggered by physical vastness. During the early childhood, stimuli that provoke a need for cognitive accommodation should trigger epistemic emotions such as curiosity, interest, or uncanny, rather than awe since children would lack perception of vastness. Drawing very young children's attention on stimuli known to elicit awe, such as an awe-inspiring landscape, may yet be profitable for them because of the curiosity and interest that usually come along with this kind of stimuli. These more basic epistemic emotions have been shown to be strongly involved in knowledge exploration, explanation-seeking, and learning (see Muis et al., 2018; Vogl et al., 2019, 2020; Liquin and Lombrozo, 2020).

Awe experiences should progressively become more noticeable during middle childhood. From 4 to 7 years, self-awareness takes on more psychological manifestations. Abstract thinking and self-reflection abilities increase and may allow perception of conceptual (rather than only physical) vastness. Moreover, children of these ages progressively realize that significant others can evaluate them (see Harter, 2015). However, they cannot yet critically evaluate themselves and lack the cognitive ability to engage in social comparisons for self-evaluation purpose; holding an evaluation of the self and that of another in mind simultaneously in order to be compared exceed he cognitive ability of young children. Consequently, self-perception is unrealistically positive; children overestimate various of their competencies by focusing on virtuosity such as power and success (see Harter, 2006, 2015; Diehl et al., 2011). This normal manifestation of narcissism and egocentrism may limit the perception of vastness and so the emergence of awe experiences as well as their consequences (e.g., on humility and knowledge exploration).

Between the ages of 8 and 10, children show a more mature sense of self-continuity and of agency, and are able to form abstract and stable concepts. Narcissism and egocentrism gradually fade, and children become at times ashamed of the self. Moreover, cultural self, which refers to a sense of self as belonging to a larger community, expands during these years (Nelson, 2003). Finally, Children who are entering early adolescence show intense self-consciousness, greater introspection as well as self-reflection, and an increasing of social awareness. As cognitive and self-development progress, children should be more prone to experience awe. Indeed, in late childhood and early adolescence, children may perceive conceptual vastness and may be able to define themselves as belonging to larger entities, as well as to compare selfrepresentations to the power or vastness of an abstract stimulus. At these ages, awe experiences may be particularly 
profitable for explanation-seeking and explorative behaviors underlying learning.

\section{DISCUSSION}

The present article aimed to qualify the assumptions of Valdesolo et al. (2017), who claimed that the accommodative component of the awe experience distinguishes it from other epistemic emotions, and that awe may be deeply involved in the process of early learning. In the first part, features of awe and its differences with epistemic emotions were examined. Two appraisals are needed to be met to experience awe: perceived vastness and a need for knowledge restructuring (Keltner and Haidt, 2003; Shiota et al., 2007; Campos et al., 2013). The need for knowledge restructuring seems to be a common feature of all epistemic emotions (Campos et al., 2013; Vogl et al., 2019; see also Muis et al., 2018), therefore what distinguishes the awe experience from other related epistemic emotional experiences is more probably the physical or conceptual vastness of its elicitors (Keltner and Haidt, 2003; Campos et al., 2013). Indeed, unlike curiosity or confusion, awe has been classified as a self-transcendent emotion, that is an emotion triggered by what is greater than the self and beyond its perceived boundaries (Shiota et al., 2014).

In the second part, we made conjectures about the emergence and development of awe in childhood. Perceiving something greater than the self presupposes stable representations of the self and the ability to compare the stimulus to those representations. In other words, awe should emerge and develop alongside with self-development. Consequently, in early childhood, stimuli that provoke a need for cognitive accommodation should trigger epistemic emotions such as curiosity, interest, or uncanny, rather than awe since young children lack self-awareness and

\section{REFERENCES}

Bai, Y., Maruskin, L. A., Chen, S., Gordon, A. M., Stellar, J. E., McNeil, G. D., et al. (2017). Awe, the diminished self, and collective engagement: universals and cultural variations in the small self. J. Pers. Soc. Psychol. 113, 185-209. doi: $10.1037 / \mathrm{pspa0000087}$

Bai, Y., Ocampo, J., Jin, G., Chen, S., Benet-Martinez, V., Monroy, M., et al. (2021). Awe, daily stress, and elevated life satisfaction. J. Pers. Soc. Psychol. 120, 837-860. doi: $10.1037 /$ pspa0000267

Brannon, E. M., Lutz, D., and Cordes, S. (2006). The development of area discrimination and its implications for number representation in infancy. Dev. Sci. 9, 59-64. doi: 10.1111/j.1467-7687.2006.00530.x

Büssing, A., Recchia, D. R., Dienberg, T., Surzykiewicz, J., and Baumann, K. (2021). Awe/gratitude as an experiential aspect of spirituality and its association to perceived positive changes during the Covid-19 pandemic. Frontiers 12, 642716. doi: 10.3389/fpsyt.2021.642716

Campos, B., Shiota, M. N., Keltner, D., Gonzaga, G. C., and Goetz, J. L. (2013). What is shared, what is different? Core relational themes and expressive displays of eight positive emotions. Cogn. Emot. 27, 37-52. doi: 10.1080/02699931.2012.683852

Cordaro, D. T., Keltner, D., Tshering, S., Wangchuk, D., and Flynn, L. M. (2016). The voice conveys emotion in ten globalized cultures and one remote village in Bhutan. Emotion 16, 117-128. doi: 10.1037/emo0000100

Diehl, M., Youngblade, L. M., Hay, E. L., and Chui, H. (2011). “The development of self-representations across the lifespan," in Handbook of Life-Span Development, self-reflection. Awe may, like other self-awareness dependent emotions, not emerge until 18-24 months. Indeed, early forms of embarrassment do not occur until 18-24 months, and more complex self-conscious emotions such as pride and shame would only emerge around 4 years, alongside with self-awareness and self-reflection development (for review see Tracy and Robins, 2004). Awe would thus be involved in the process of learning later in development than more basic epistemic emotions such as curiosity and interest.

Despite the arguments discussed in the present paper, to date no empirical evidence confirmed that the emergence and development of awe would depend on self-development. I hope researchers will grasp the important theoretical and practical implications of this topic and that empirical research on awe in childhood will be conducted. Recent experiments suggest that awe would exhibit distinct facial expression, non-verbal emotional vocalizations, and autonomic nervous system responding (Shiota et al., 2011; Campos et al., 2013; Cordaro et al., 2016) that could be used as cues to assess awe experiences in young children. It would also be interesting to investigate whether the consequences of awe are the same in adults and children. For example, awe has been found to promote prosociality and humility in adults (e.g., Prade and Saroglou, 2016; Stellar et al., 2018); this effect may be weaker in young children with high levels of narcissism and egocentrism (see Harter, 2015).

\section{AUTHOR CONTRIBUTIONS}

The author confirms being the sole contributor of this work and has approved it for publication. eds K. L. Fingerman, C. A. Berg, J. Smith, and T. C. Antonucci (Berlin: Springer Publishing), 611-656.

Gocłowska, M. A., Elliot, A. J., van Elk, M., Bulska, D., Thorstenson, C. A., and Baas, M. (2021). Awe arises in reaction to exceeded rather than disconfirmed expectancies. Emotion. doi: 10.1037/emo0001013. [Epub ahead of print].

Harter, S. (2006). "The self," in Handbook of Child Psychology: Vol. 3. Social, Emotional, and Personality Development, eds R. M. Lerner, W. Damon, and N. Eisenberg (Hoboken, NJ: John Wiley), 505-569.

Harter, S. (2015). "Emerging self-processes during childhood and adolescence," in Handbook of Self and Identity, Second Edition, eds M. R. Leary and J. P. Tangney (New York, NY: Guilford), 680-715.

Ji, Q., Janicke-Bowles, S. H., De Leeuw, R. N. H., and Oliver, M. B. (2019): The melody to inspiration: the effects of awe-eliciting music on approach motivation and positive well-being. Media Psychol. 24, 305-331. doi: 10.1080/15213269.2019.1693402

Keltner, D., and Haidt, J. (2003). Approaching awe, a moral, spiritual, and aesthetic emotion. Cogn. Emot. 17, 297-314. doi: 10.1080/02699930302297

Liquin, E. G., and Lombrozo, T. (2020). Explanation-seeking curiosity in childhood. Curr. Opin. Behav. Sci. 35, 14-20. doi: 10.1016/j.cobeha.2020.05.012

Morin, A. (2021). Implications of mirror self-recognition for self-awareness. Psychol. Conscious. Theory Res. Pract. doi: 10.1037/cns0000270. [Epub ahead of print].

Muis, K. R., Chevrier, M., and Singh, C. A. (2018). The role of epistemic emotions in personal epistemology and self-regulated learning. Educ. Psychol. 53, 165-184. doi: 10.1080/00461520.2017.1421465 
Negami, H. R., and Ellard, C. G. (2021). How architecture evokes awe: predicting awe through architectural features of building interiors. Psychol. Aesth. Creat. Arts. doi: 10.1037/aca0000394. [Epub ahead of print].

Nelson, K. (2003). "Narrative and self, myth and memory: Emergence of the cultural self," in Autobiographical Memory: And the Construction of a Narrative Self, eds R. Fivush and C. A. Haden (Erlbaum), 3-28.

Piaget, J., and Inhelder, B. (1969). The Psychology of the Child. New York, NY: Basic Books.

Piff, P. K., Dietze, P., Feinberg, M., Stancato, D. M., and Keltner, D. (2015). Awe, the small self, and prosocial behavior. J. Pers. Soc. Psychol. 108, 883-899. doi: $10.1037 /$ pspi0000018

Prade, C., and Saroglou, V. (2016). Awe's effects on generosity and helping. J. Posit. Psychol. 11, 522-530. doi: 10.1080/17439760.2015.1127992

Rochat, P. (2003). Five levels of self-awareness as they unfold early in life. Conscious. Cogn. 12, 717-731. doi: 10.1016/S1053-8100(03)00081-3

Rudd, M., Vohs, K., and Aaker, J. (2012). Awe expands people's perception of time, alters decision making, and enhances well-being. Psychol. Sci. 23, 1130-1136. doi: 10.1177/0956797612438731

Saroglou, V., Buxant, C., and Tilquin, J. (2008). Positive emotions as leading to religion and spirituality. J. Posit. Psychol. 3, 165-173. doi: 10.1080/17439760801998737

Shiota, M. N., Keltner, D., and Mossman, A. (2007). The nature of awe: elicitors, appraisals, and effects on self-concept. Cogn. Emot. 21, 944-963. doi: 10.1080/02699930600923668

Shiota, M. N., Neufeld, S. L., Yeung, W. H., Moser, S. E., and Perea, E. F. (2011). Feeling good: autonomic nervous system responding in five positive emotions. Emotion 11, 1368-1378. doi: 10.1037/a0024278

Shiota, M. N., Thrash, T. M., Danvers, A. F., and Dombrowski, J. T. (2014). "Transcending the self: awe, elevation, and inspiration," in Handbook of Positive Emotions,eds M. M. Tugade, M. N. Shiota, and L. D. Kirby (New York, NY: Guilford), pp. 362-377.

Silvia, P. J. (2010). Confusion and interest: the role of knowledge emotions in aesthetic experience. Psychol. Aesth. Creat. Arts 4, 75-80. doi: 10.1037/a0017081

Stancato, D. M., and Keltner, D. (2021). Awe, ideological conviction, and perceptions of ideological opponents. Emotion 21, 61-72. doi: $10.1037 /$ emo0000665

Stellar, J. E., Gordon, A., Anderson, C. L., Piff, P. K., McNeil, G. D., and Keltner, D. (2018). Awe and humility. J. Pers. Soc. Psychol. 114, 258-269. doi: $10.1037 /$ pspi0000109
Sturm, V. E., Datta, S., Roy, A. R. K., Sible, I. J., Kosik, E. L., Veziris, C. R., et al (2020). Big smile, small self: awe walks promote prosocial positive emotions in older adults. Emotion. doi: 10.1037/emo0000876. [Epub ahead of print].

Tracy, J. L., and Robins, R. W. (2004). Putting the self into selfconscious emotions: a theoretical model. Psychol. Inq. 15, 103-125. doi: 10.1207/s15327965pli1502_01

Valdesolo, P., Shtulman, A., and Baron, A. S. (2017). Science is awe-some: the emotional antecedents of science learning. Emotion Rev. 9, 215-221. doi: $10.1177 / 1754073916673212$

Van Cappellen, P., and Saroglou, V. (2012). Awe activates religious and spiritual feelings and behavioral intentions. Psycholog. Relig. Spirit. 4, 223-236. doi: $10.1037 / \mathrm{a} 0025986$

Vogl, E., Pekrun, R., Murayama, and, K., and Loderer, K. (2020). Surprisedcurious-confused: epistemic emotions and knowledge exploration. Emotion 20, 625-641. doi: 10.1037/emo0000578

Vogl, E., Pekrun, R., Murayama, K., Loderer, K., and Schubert, S. (2019). Surprise, curiosity, and confusion promote knowledge exploration: evidence for robust effects of epistemic emotions. Front. Psychol. 10, 2474. doi: 10.3389/fpsyg.2019.02474

Zhao, H., Zhang, H., Xu, Y., Lu, J., and He, W. (2018). Relation between awe and environmentalism: the role of social dominance orientation. Front. Psychol. 9, 2367. doi: 10.3389/fpsyg.2018.02367

Conflict of Interest: The author declares that the research was conducted in the absence of any commercial or financial relationships that could be construed as a potential conflict of interest.

Publisher's Note: All claims expressed in this article are solely those of the authors and do not necessarily represent those of their affiliated organizations, or those of the publisher, the editors and the reviewers. Any product that may be evaluated in this article, or claim that may be made by its manufacturer, is not guaranteed or endorsed by the publisher.

Copyright (C) 2022 Prade. This is an open-access article distributed under the terms of the Creative Commons Attribution License (CC BY). The use, distribution or reproduction in other forums is permitted, provided the original author(s) and the copyright owner(s) are credited and that the original publication in this journal is cited, in accordance with accepted academic practice. No use, distribution or reproduction is permitted which does not comply with these terms. 